\title{
O PIBID E A MOTIVAÇÃO DOS ALUNOS EM AULAS DE LÍNGUA INGLESA
}

\author{
Márcia Volani Cordova de Oliveira ${ }^{1}$ \\ Likelli Simão Bender ${ }^{2}$ \\ Luciane Baretta ${ }^{3}$
}

Apresentação

Quando discorremos acerca do processo de ensino e aprendizagem da língua inglesa em escolas públicas, torna-se necessário ponderar sobre o que tem sido feito para que os alunos se interessem pela disciplina, pois a sua motivação no estudo de uma língua estrangeira é um dos componentes essenciais para que o aprendizado ocorra (PINHEIRO; OLIVEIRA; GOMES, 2016).

O relato que se segue visa apresentar a importância do trabalho e os benefícios proporcionados pelo Programa Institucional de Bolsas de Iniciação à Docência - PIBID, na motivação e interesse pelas aulas de língua inglesa, a partir da construção de sequências didáticas com base nos estudos de Dolz, Noverraz e Schneuwly (2004), desenvolvidas em parceria com a Universidade Estadual do Centro-Oeste, UNICENTRO, e duas escolas de educação básica da rede pública de ensino, que foram contempladas com o programa no ano de 2016.

Para tal, apresentam-se brevemente as sequências didáticas desenvolvidas pelos pibidianos e apontam-se os principais benefícios percebidos pelas professoras supervisoras, assim como, são apresentados dados oriundos de enquetes desenvolvidas pelas professoras em sala de aula, com a finalidade de avaliar se os alunos também se sentiram mais motivados e com menos dúvidas, após o início das atividades do PIBID nas aulas de língua inglesa.

Acredita-se que a presença do PIBID na escola é fundamental, na medida em que proporciona o diálogo entre a escola, por meio das professoras supervisoras, e a universidade, por meio dos alunos professores em formação, que em conjunto, a partir de sua vivência no ambiente escolar, propõem atividades diversificadas e significativas.

\footnotetext{
${ }^{1}$ Mestranda em Letras (UNICENTRO), supervisora do subprojeto PIBID-Inglês (Guarapuava- Pr) e professora da rede pública estadual de ensino. marcia_volani@yahoo.com.br.

${ }^{2}$ Mestra em Letras (UNICENTRO) supervisora do subprojeto PIBID-Inglês (Guarapuava-PR) durante o ano de 2016 e professora da rede pública estadual de ensino. likelli_simao@yahoo.com.br.

${ }^{3}$ Doutora em Letras (UFSC). Professora do curso de Letras Inglês e do Mestrado em Letras (UNICENTRO); coordenadora do subprojeto PIBID-Inglês de maio/2016 a fevereiro/2017. barettaluciane@gmail.com.
} 
No caso do PIBID-Letras Inglês, as atividades trabalhadas em sala são planejadas a partir da observação dos interesses, necessidades e conhecimento prévio dos alunos com relação à língua inglesa. Feito este diagnóstico, os alunos professores desenvolvem um trabalho em conjunto com as professoras supervisoras e a coordenação do Subprojeto, de planificações didático-pedagógicas, suporte nas atividades em sala de aula (fazendo uso de diferentes metodologias de ensino), e da prática de ensino por meio de gêneros textuais (STUTZ, 2014), aumentando o interesse dos alunos pela disciplina, sua motivação para aprender e, consequentemente, seu aprendizado.

\section{Caracterização das Escolas}

Os trabalhos do grupo PIBID-Inglês da UNICENTRO, no ano de 2016, foram desenvolvidos em duas escolas públicas da cidade de Guarapuava-Pr, localizadas em bairros periféricos; ambas oferecem à comunidade ensino fundamental e médio, além de projetos desenvolvidos no contraturno escolar.

As escolas contempladas provêm de uma classe econômica pouco favorecida e as comunidades em que elas se localizam enfrentam diversos problemas como a falta de infraestrutura e a violência proveniente do envolvimento com o tráfico de drogas. Em relação às famílias dos alunos, a maioria dos pais possui baixo grau de escolaridade, o que ocasiona altos índices de repetência e evasão escolar, pois geralmente os filhos mais velhos precisam trabalhar para complementar a renda familiar. No entanto, apesar dos problemas citados, as escolas possuem um clima harmonioso e favorável ao aprendizado, já que são vistas pela comunidade como instituições respeitadas, pois oferecem aos seus alunos oportunidade de lazer, cultura e produção de conhecimento através dos projetos que oferecem à comunidade.

\section{Fundamentação teórica}

Implantado em 2012, o PIBID-Letras Inglês da UNICENTRO possui o objetivo de desenvolver seus trabalhos alternando teoria e prática no que se refere ao ensino e aprendizagem de língua inglesa, pautado nas teorias do Interacionismo Sociodiscursivo (ISD). O ISD é um quadro teórico metodológico recente, desenvolvido por pesquisadores da Universidade de Genebra, Bronckart (1999) e Dolz \& Schneuwly (2004). Seu aporte teórico advém de diversas leituras e contribuições, como os conceitos de aprendizagem e desenvolvimento no ensino de línguas segundo Vygostky (1993), e a abordagem discursiva de Bakhtin (1992). Sendo assim, o ISD possui como enfoque a relação entre as atividades humanas, os textos e os discursos, aprofundando o estudo sobre a interação entre linguagem, pensamento e agir humano (BRONCKART, 2007). 
Os trabalhos desenvolvidos pelo grupo PIBID-Inglês adotam a proposta de transposição didática com base em gêneros textuais, com ações voltadas para leitura e discussão de saberes institucionais como os documentos oficiais, saberes sobre gêneros textuais, construção de modelos e sequências didáticas, contribuindo assim para a formação de futuros profissionais da língua inglesa, além de propiciar aos alunos das escolas públicas o contato com novas metodologias de ensino. Nesse sentido, as Sequências Didáticas são concebidas como um conjunto de atividades organizadas para realizar a transposição didática de conhecimentos que envolvem o uso de gêneros textuais, suas esferas de produção e circulação (CRISTOVÃO, 2009; STUTZ, 2014). As Sequências Didáticas (SDs) podem ser divididas em módulos compostos por atividades progressivas contendo objetivos específicos que desenvolvam as capacidades de linguagem necessárias para a compreensão e produção de textos de um determinado gênero textual (CRISTOVÃO, STUTZ; 2011).

Dessa forma, a partir de reflexões e discussões realizadas semanalmente pelo grupo PIBIDInglês, foram elaboradas SDs abordando diversos gêneros textuais. Relatamos, a seguir, a experiência de trabalhar com duas dessas SDs em turmas de sétimo ano do ensino fundamental e de primeiro ano do ensino médio com o objetivo de exemplificar como atividades planejadas especificamente para cada turma podem ampliar o interesse dos alunos pelo estudo da língua inglesa.

\section{Descrição da experiência}

O grupo PIBID-Inglês da UNICENTRO elaborou, em conjunto com 10 alunos professores do curso de Letras Inglês, duas professoras supervisoras que desenvolvem seus trabalhos com a língua inglesa em escolas públicas, e duas professoras coordenadoras, integrantes do corpo docente do Departamento de Letras da UNICENTRO, SDs de diferentes gêneros textuais, a partir de modelos didáticos (STUTZ, 2014), produzidos com base nos estudos de Dolz, Noverraz e Schneuwly (2004), para serem aplicadas nas turmas das escolas contempladas pelo Programa.

Neste relato fazemos menção a quatro turmas, duas de cada escola, como representativas para descrevermos e avaliarmos o trabalho desenvolvido pelo grupo do PIBID-Inglês; estas turmas responderam a uma enquete com questões relacionadas à atuação do PIBID nas escolas. Para as turmas que não tinham a atuação de pibidianos em sala, perguntamos se ouviam comentários a respeito do PIBID-Inglês, de colegas que estão nas turmas contempladas pelo programa; indagamos também se gostariam de ter alunos professores nas aulas de língua inglesa e se acreditavam que poderiam sair com menos dúvidas e mais motivados das aulas, se houvessem pibidianos desenvolvendo trabalhos em conjunto com a professora em sua sala de aula. Para as turmas com a atuação do PIBID, perguntamos se acreditavam que o desempenho deles nas aulas de inglês melhorou desde que o Pibid começou a atuar na turma; se ficavam com menos dúvidas nas atividades, após o 
trabalho do PIBID em sala; e se eles se sentiam mais motivados a aprender a língua inglesa desde que os pibidianos iniciaram os trabalhos em sua turma.

$\mathrm{Na}$ escola $\mathrm{A}$, foram escolhidos dois sétimos anos do ensino fundamental: um que teve a atuação do PIBID em sala de aula e outro que não teve. Da mesma forma, na escola B, os trabalhos foram realizados em dois primeiros anos do ensino médio, uma turma contemplada com o PIBID e outra não, para que a partir desse contexto de análise das turmas (com e sem a atuação do grupo do PIBID), fosse possível comparar o nível de interesse e motivação dos alunos pela disciplina a partir das atividades propostas e desenvolvidas pelos alunos professores.

De maneira geral, a atuação dos pibidianos em ambas as escolas ocorreu por meio do auxílio nas tarefas e práticas pedagógicas das professoras supervisoras e também com a aplicação de SDs nas turmas nas quais o PIBID se inseriu, possibilitando a construção das tarefas de ensino e de aprendizagem, sendo elas dispostas de forma sequencial e em complexidade crescente, com base nas capacidades de linguagem e desenvolvimento dos alunos.

Para o sétimo ano, na escola A, foi desenvolvida a SD do gênero Video Game Advertisements (propagandas de videogame), enquanto para a primeira série do ensino médio, na escola $B$, foi trabalhada a SD do gênero Sitcom (seriado). Nas outras duas turmas, que não tiveram a participação dos pibidianos em sala, foram trabalhadas atividades do livro didático e atividades extras, algumas delas, desenvolvidas pelos pibidianos para as turmas nas quais atuam, porém adaptadas e utilizadas pelas professoras supervisoras nas turmas que não possuem a atuação do PIBID.

No sétimo ano que teve atuação do PIBIB, os alunos conheceram o gênero textual propaganda de videogame e seus principais elementos composicionais. A escolha do gênero ocorreu pelo fato de apresentar grande circulação e estar próximo da realidade e interesse dos alunos desta faixa etária (SENEM, 2014). Segundo descrito no modelo didático para o gênero anúncio publicitário, que fundamentou a construção da SD trabalhada em sala de aula, um anúncio publicitário geralmente possui título, texto, slogan e imagem utilizando-se da retórica, com um propósito argumentativo, para persuadir o leitor/consumidor (SENEM, 2014). Ainda, o anúncio apresenta um tema central, que confere uma unidade temática e uma estrutura circular, isto é, o tema inicia e acaba no título (exórdio). Há de ser considerada também a escolha lexical nos anúncios, visto que é ideológica e tenta convencer o leitor por meio dos termos utilizados (SENEM, 2014).

Tendo-se em vista todas as características citadas, a SD desenvolvida por um dos pibidianos, é composta por 17 páginas e 38 atividades de diferentes tipos. A SD foi dividida em três módulos, sendo o primeiro deles destinado à apresentação do gênero, enriquecimento de vocabulário e comparação entre anúncios publicitários de videogame antigos e modernos. No segundo módulo, os alunos realizaram atividades com enfoque em anúncios modernos, aprendendo (novo) vocabulário e as partes constitutivas do gênero. Ao final do módulo, desenvolveram o que foi denominado 
"produção intermediária" que consiste na produção de um anúncio de videogame por aluno como suporte para a produção final, ao término da SD. No terceiro módulo, os alunos aprenderam a utilizar o verbo em sua forma imperativa ( $g o$, buy, play), recorrente nos exemplos analisados e finalizaram a produção do anúncio, retomando as ideias da produção intermediária e levando em consideração os apontamentos feitos pelo pibidiano e pela professora supervisora. Houve ainda, o cuidado da elaboração de atividades extras, ao fim da SD, para que o aluno não ficasse ocioso, entre as atividades propostas. Estas atividades têm como enfoque o lúdico, como caça-palavras, relacionar colunas, e atividades de colorir, para que o aluno se sinta motivado enquanto revisa os conteúdos trabalhados.

No primeiro ano do ensino médio, a SD do gênero textual Sitcom, mais especificamente, um episódio de Everybody hates Chris (Todo mundo odeia Cris), foi desenvolvida em conjunto por dois pibidianos. A escolha por este gênero se deu, principalmente, por ser uma prática não muito comum nas escolas, isto é, as habilidades de compreensão oral são menos valorizadas pelo ambiente escolar, apesar de fazerem parte do dia-a-dia dos estudantes, que assistem sitcoms. Dessa forma, ao se trabalhar com o sitcom, é trazido o cotidiano para a sala de aula, valorizando o conhecimento prévio dos alunos, permitindo que eles se apropriem de forma mais detalhada das capacidades de linguagem presentes no trabalho com esse gênero, ampliando seu conhecimento e tornando o aprendizado mais prazeroso e significativo.

O trabalho com a SD (12 páginas e 23 atividades) foi iniciado com a explanação do objetivo da sequência de atividades, a fim de nortear e especificar o trabalho com o gênero. Em seguida, foi realizado um diagnóstico, por meio de conversa com os alunos, para verificar o seu nível de conhecimento acerca do gênero, com o propósito de reconhecer o contexto e o ponto de partida em que se faz necessária a intervenção, bem como o caminho que o aluno precisa percorrer no desenvolvimento do trabalho, para que ocorra a efetivação entre o conhecimento prévio e o que pode ser aprendido por meio da SD. O desenvolvimento da SD prosseguiu com o reconhecimento dos elementos característicos do sitcom, como: o número limitado de personagens e cenários comuns no cotidiano, como por exemplo, casa e escola; o uso de frases que se repetem e contribuem para a caracterização de personagens estereotipados, que produzem o tom humorístico do gênero; a exploração e reconhecimento do cenário, figurino e modos de interpretação. Tais elementos específicos são importantes no reconhecimento deste gênero, pois a partir desses elementos, os alunos percebem, por meio das atividades propostas na SD, que este é permeado por turnos de fala, pelos gestos e entonação, pelas situações que derivam de diferentes culturas, assim como a integração da linguagem visual e sonora, que contribuem para alargar a compreensão da língua inglesa pelo aluno.

No episódio assistido, Everybody Hates Mother's Day (Todo Mundo Odeia o Dia das Mães), o tema preconceito racial é fortemente abordado, o que permitiu realizar discussões e reflexões acerca do preconceito ainda existente em nosso contexto, promovendo o despertar da criticidade do aluno, 
estabelecendo comparações entre a cultura dos contextos brasileiro e americano. As figuras de linguagem como as expressões idiomáticas (Up the creek, Holy cow!), recorrentes no gênero foram trabalhadas com o intuito de demonstrar a informalidade do discurso oral e auxiliar no processo de inferenciação para a compreensão geral do texto.

Deste modo, ao término do trabalho com a SD, os alunos se apropriaram de maneira mais detalhada das capacidades de linguagem presentes no trabalho com o sitcom, ampliando, além de seu conhecimento com relação ao gênero, a compreensão em língua inglesa de forma significativa, efetivando o elo entre o cotidiano dos estudantes e o conteúdo trabalhado em sala de aula, conforme objetivo proposto para esta SD.

A partir da comparação dos trabalhos realizados nas turmas com e sem a atuação do PIBID, foi possível comparar os resultados do ponto de vista dos alunos e chegarmos a algumas conclusões sobre o processo de ensino-aprendizagem e motivação pelas aulas de língua inglesa, conforme apresentamos a seguir.

\section{Avaliação dos resultados}

Por meio da comparação do contexto de análise das turmas com e sem a atuação do PIBID, o aumento do interesse dos alunos pelas aulas de língua inglesa, ao trabalharem com as SDs propostas foi visível, tanto no sétimo ano do fundamental, quanto na primeira série do médio.

Por meio da análise dos dados da enquete, verificou-se que os alunos das turmas não contempladas pelo PIBID gostariam de ter a experiência tal qual seus colegas: $47 \%$ dos alunos do $7^{\circ}$ ano e $63 \%$ dos alunos do $1^{\circ}$ ano do ensino médio; esses alunos reportaram que ouvem elogios entusiasmados dos outros alunos sobre a atuação dos pibidianos nas aulas de língua inglesa, demonstrando que há uma imagem positiva em relação ao programa no ambiente escolar.

Pela percepção das professoras supervisoras, a presença dos pibidianos contribuiu significativamente para ampliar o conhecimento dos alunos nas aulas de língua inglesa, bem como sua autonomia para realizar as atividades, pois as SDs propostas estavam adequadas à competência linguística dos alunos, os gêneros trabalhados (propaganda de vídeo game e sitcom) e os temas abordados (jogos eletrônicos e racismo) estavam mais próximos da realidade e da faixa etária dos alunos.

Pode-se afirmar que o grupo do PIBID colaborou, especialmente, para a ampliação da motivação dos alunos, sendo que $79 \%$ dos alunos do $7^{\circ}$ ano e $74 \%$ dos alunos do $1^{\circ}$ ano do ensino médio reportaram que acreditam que as aulas ficaram melhores após o início das atividades com o Pibid. Em ambas as turmas em que os pibidianos atuaram, durante o ano letivo de 2016, foi perceptível a mudança no comportamento dos alunos em sala de aula para melhor; após a chegada dos alunos 
professores, foi perceptível também, o maior comprometimento dos alunos com a realização das atividades propostas, provavelmente porque eles se sentiam mais confortáveis em solicitar esclarecimentos aos pibidianos quando não entendiam ou estavam em dúvida com relação a determinado conteúdo ou atividade $\left(42 \%\right.$ dos alunos do $7^{\circ}$ ano e $48 \%$ dos alunos do $1^{\circ}$ ano do ensino médio relataram não ficarem com dúvidas após o início da atuação dos pibidianos nas aulas).

Assim, verificou-se que ocorreu significativa melhora no processo de ensino-aprendizagem de língua inglesa, e também o aumento da motivação pelas aulas a partir da atuação do PIBID, tanto na percepção das professoras, quanto na percepção dos alunos.

\section{Considerações finais}

Diante do (breve) relato de experiência aqui apresentado, foi possível perceber a importância do trabalho e os benefícios proporcionados pelo PIBID na motivação e no aprimoramento do aprendizado nas aulas de língua inglesa, por meio da produção e trabalho com sequências didáticas desenvolvidas especialmente para as turmas atendidas pelo programa.

Segundo Crookes e Schmidt (1991), a motivação controla o envolvimento e a persistência na realização de tarefas, e pode ser percebida em alguns alunos de forma mais presente que em outros. No entanto, atividades interessantes e especialmente desenhadas para as turmas, podem aumentar a motivação para aprender e isso foi visível com o trabalho realizado pelos pibidianos. Sendo assim, ficou evidente que o papel do educador é fundamental nesse processo de ensino e aprendizagem (ALMEIDA; MIRANDA; GUISANDE, 2008) e nesse sentido, estudantes-professores em formação têm muito a contribuir por meio do PIBID, pois além de haver mais um professor em sala para esclarecer as dúvidas dos alunos e auxiliá-los na execução das atividades propostas, os pibidianos desenvolvem atividades interessantes, significativas e especialmente projetadas para as turmas, partindo da necessidade de desenvolver práticas que considerem o conhecimento do aluno, os contextos de uso e de circulação da língua, permitindo dessa forma, aumentar o interesse e a motivação para aprender.

Com relação à experiência como professoras supervisoras do PIBID, percebemos que nossa função nos permite o aperfeiçoamento da prática pedagógica e desenvolvimento profissional, na medida em que proporciona a ampliação da postura investigativa e reflexiva, a aprendizagem de novas metodologias de ensino e a utilização de recursos didáticos diferentes dos quais eram utilizados nas aulas antes da participação no PIBID. Além disso, o programa nos permitiu aumentar a participação em eventos da área de ensino e aprendizagem, bem como a produção de artigos científicos e relatos, que em conjunto com os pibidianos, resultam na participação em eventos científicos e na disseminação do saber. 
Dessa forma, a função de supervisão do PIBID funciona como uma ponte entre a escola e a universidade, aliando teoria e prática, contribuindo efetivamente para a formação e o desenvolvimento profissional tanto dos alunos-professores em formação, quanto dos professores supervisores, que são profundamente impactados por esta experiência, que promove mudanças concretas e significativas em sua atuação profissional, permitindo a elevação da qualidade de ensino da escola pública.

Referências

ALMEIDA, L. S.; MIRANDA, L.; GUISANDE, M. A. Atribuições causais para o sucesso e fracasso escolares. Estudos em Psicologia, 25(2), 169-176, 2008.

BAKHTIN, M. Os gêneros do discurso. In: Estética da criação verbal. Trad. Maria Ermantina Galvão Gomes e Pereira. São Paulo: Martins Fontes, 1992.

BRONCKART, J. P. Atividade de linguagem, textos e discursos: por um interacionismo sociodiscursivo. Trad. Anna Rachel Machado, Péricles Cunha. 2. ed. São Paulo: Educ, 2007 [1999].

CROOKES, G.; SCHMIDT, R. Motivation: Reopening the research agenda. Language Learning, 41, 469512,1991

DOLZ, J.; NOVERRAZ, M.; SCHNEUWLY, B. As sequências didáticas para o oral e a escrita: apresentação de um procedimento. Roxane Rojo e Glaís S. Cordeiro (Trad.). Campinas, SP: Mercado das Letras, 2004

CRISTOVÃO, V. L. L. Sequências didáticas para o ensino de línguas. In: DIAS, R.; CRISTOVÃO, V.L.L. (Org.). O livro didático de língua estrangeira. Campinas/SP: Mercado das Letras, 2009, p. $305-344$.

CRISTOVÃO, V. L. L. ; STUTZ, L. . Sequências Didáticas: semelhanças e especificidades no contexto francófono como L1 e no contexto brasileiro como LE. In: Paula Tatianne Carréra Szundy; Júlio Cesar Araújo; Christine Siqueira Nicolaides; Kleber Aparecido da Silva. (Org.). Linguística Aplicada e Sociedade: ensino e aprendizagem de línguas no contexto brasileiro. Campinas: Pontes Editores, 2011, v. 1 , p. $17-40$.

PINHEIRO, I. C. M.; OLIVEIRA M. L.; GOMES, J. X. L. A construção da motivação nas aulas de língua inglesa: uma pesquisa-ação na escola pública. Disponível em: http://200.129.241.80/revlinbt/wpcontent/uploads/2013/10/a constru\%C3\%A7\%C3\%A3o-da-motiva\%C3\%A7\%C3\%A3o-nas-aulas-delingua-inglesa.pdf Acesso 17 de outubro de 2016.

SENEM, J. Modelo didático do gênero anúncio publicitário. IN: STUTZ, L. (org.). Modelos didáticos de gêneros textuais: as construções dos alunos professores do PIBID Letras Inglês. São Paulo: Pontes Editores, 2014, p. 57-74.

STUTZ, L. Apresentação do PIBID Letras-Inglês. IN: STUTZ, L. (org.). Modelos didáticos de gêneros textuais: as construções dos alunos professores do PIBID Letras Inglês. São Paulo: Pontes Editores, 2014, p. 17-30. 
STUTZ, L. Sequências didáticas, socialização de diários e autoconfrontação: instrumentos para formação inicial de professores de inglês. Tese (Doutorado em Estudos da Linguagem). Universidade Estadual de Londrina, 2012.

VYGOTSKY, L. S. Pensamento e Linguagem. São Paulo: Martins Fontes, 1993. 